\title{
LIMITES AOS EFEITOS À DECISÃO DO SUPREMO TRIBUNAL FEDERAL NO CONTROLE DIFUSO DE CONSTITUCIONALIDADE
}

CIRO ROSA DE OLIVEIRA 


\section{LIMITES AOS EFEITOS À DECISÃO DO SUPREMO TRIBUNAL FEDERAL NO CONTROLE DIFUSO DE CONSTITUCIONALIDADE}

\section{RESUMO}

0 presente trabalho tem como objetivo demonstrar os limites impostos à decisão definitiva do Supremo Tribunal Federal quanto à Lei declarada inconstitucional, de maneira incidental, posto que a competência é privativa do Senado Federal, através de resolução, para suspender a execução dessa Lei, no todo ou em parte, após comunicação da decisão, sendo um ato discricionário do Senado e a partir daí produz efeitos erga omnes.

\section{RESUMEN}

El presente trabajo tiene como objtetivo demostrar los limites impuestos a la decisión definitiva del Supremo Tribunal Federal cuando la Ley declara inconstitucional, de manera acidental, puesto que la competência es privativa del Senado Federal, através de la resolución para suspender la ejecución de esa Ley, en todo o en parte, despues de la decisión, siendo un acto discricionário del Senado e de entonces encendido para producir omnes de los aumentos del efecto.

\footnotetext{
${ }^{1}$ Graduado em Direito, Pós-Graduando do Curso de Direito Constitucional Lato Sensu da Instituição Unitins - Fundação Universidade do Tocantins. Texto orientado pela Professora DSc. Noêmia Porto.
} 


\section{INTRODUÇÃO}

O controle de Constitucionalidade das Leis, the judcial review of legislation, teve origem nos Estados Unidos da América, depois de uma exaustiva reflexão acerca da supremacia da Constituição sobre as leis ordinárias.

Essa contribuição é "tão importante quanto à do federalismo e do sistema presidencial de governo, formas políticas também desconhecidas até o advento do sistema republicano nos Estados Unidos" (BONAVIDES, 2003, p. 305).

Dessa forma, o princípio da exigência de compatibilidade das leis com a Constituição ocorreu pela primeira vez na famosa decisão do Juiz John Marshall no caso Willian Marbury v. James Madison no ano de 1803.

Nela o Tribunal entendeu que embora o Poder Judiciário não tivesse competência legislativa, competia a ele invalidar a lei Inconstitucional, pois não podia a vontade do Poder Constituinte ser suprimida pela vontade do legislador ordinário, pois esta devia curvar-se às diretrizes daquela, asseverando que ao congresso e ao presidente competia a tarefa de editar e validar a norma, contudo por um descuido dos mesmos esqueceram desse óbice imposto pela Constituição, assim cabia ao Judiciário solucionar os casos concretos que lhes fossem submetidos e rechaçar a norma incompatível com a Constituição face à supremacia desta sobre àquela.

Logo não podia a Constituição ser revogada na parte em que fosse atingida pela lei ordinária, todavia esta é que deveria ser tida por inexistente, na parte em que conflitasse com a Constituição, ante à cristalina inconstitucionalidade.

Assim a regra de que a lei posterior revogava a lei anterior não se aplicava à Constituição, por ser essa hierarquicamente superior àquela.

Em ocorrendo essa hipótese, a decisão dava efeito de inaplicabi- 
lidade da lei ordinária, mesmo sendo esta posterior à Constituição.

No século XX surgiu o sistema concentrado de controle político de constitucionalidade, cujos parâmetros teóricos, basicamente, foram traçados e delineados por Hans Kelsen e, sob seu comando, inseridos na Constituição da Áustria de 1921, precursora desse sistema em nível constitucional.

Esse sistema fora copiado e aprimorado, por diversos países, principalmente, pelos Europeus.

Com a introdução e adoção desse sistema passou a coexistir com o sistema difuso de controle jurisdicional da constitucionalidade, tudo, com o fim específico de manter a autoridade da Constituição, sendo de suma importância para o Estado na medida em que qualquer caso concreto regido por uma determinada norma que entrasse em choque com a Constituição, seria levado o incidente ou recurso próprio a um Tribunal Supremo especial para questões constitucionais, em regra, esse Tribunal Constitucional, ainda, tinha a competência para decidir casos originários em que a inconstitucionalidade da lei é debatida em tese, sem a necessidade da ocorrência de um caso concreto específico.

\section{CONTROLE DE CONSTITUCIONALIDADE NO BRASIL}

No Brasil, pode-se afirmar que, atualmente, fora adotado o controle jurisdicional de constitucionalidade, por sistema misto, com características próprias do sistema difuso abeberando-se, em certa medida, no modelo norte-americano da Suprema Corte de Marshall e do sistema concentrado inspirando-se nas atuais Cortes Constitucionais européias, a partir do modelo austríaco de Kelsen.

A tradição brasileira de controle da constitucionalidade é a de controle difuso, cuja competência é do Poder Judiciário, sendo ela do Supremo Tribunal Federal como a última instância neste e nas demais questões. Desde a Constituição de 1934 até os dias atuais a competência, sempre, foi do Senado Federal para, através de resolução, 
suspender a execução de lei declarada inconstitucional por decisão definitiva da Suprema Corte Brasileira. Esta é uma tradição que se consolidou no constitucionalismo brasileiro, na medida em que já transcorreram mais de setenta anos dessa realidade institucional. 0 controle concentrado de constitucionalidade surgiu com a Emenda Constitucional $\mathrm{n} \times 16$, de 26 de novembro de 1965 , que deu nova redação ao art. 101 da Constituição de 1946.

Esta realidade permaneceu, praticamente, inalterada até 1988. A redação original da atual Constituição da República inseriu a ação direta de inconstitucionalidade - ADI, - a ação direta de inconstitucionalidade por omissão - ADI por omissão e a ADPF - argüição de descumprimento de preceito fundamental.

Com a Emenda Constitucional no 3 de 17 de março de 1993 foi adotada no sistema de controle concentrado da constitucionalidade a ação declaratória de constitucionalidade.

0 controle difuso (incidental), também conhecido como controle por via de exceção ou defesa tem como característica o fato de ser permitido a qualquer Juiz ou Tribunal, em qualquer processo, por iniciativa das partes, do Ministério Público, inclusive de ofício, no julgamento de um caso concreto analisar a constitucionalidade de uma lei ou ato normativo federal ou estadual, dessa forma, o Juiz ou Tribunal que estiver apreciando esse caso, ao verificar que a lei ou qualquer ato jurídico, inclusive os de natureza municipal, estiverem em desarmonia com a Constituição Brasileira têm o dever de não aplicá-los em face da inconstitucionalidade.

Contudo essa decisão, somente, tem efeito entre as partes litigantes (inter partes), não anulando, nem tornando ineficaz essas normas, pois as mesmas continuam fruindo os efeitos para as partes não envolvidas no caso sub judice.

A declaração de inconstitucionalidade é de suma importância para a solução do caso concreto, não sendo, contudo, a análise desse dispositivo o objeto principal da ação, pois é apreciado tão-somente, 
em caráter incidental. A decisão "não é feita sobre o objeto principal da lide, mas sim sobre questão prévia indispensável ao julgamento do mérito" (BASTOS, 1982, p. 59).

\subsection{DA FUNÇÃO DO SENADO FEDERAL}

A intervenção do Senado Federal é uma forma sui generis que tem o condão de aproximar o sistema difuso do concentrado, no que se refere à eficácia da norma inconstitucional.

" $O$ sistema de controle de constitucionalidade que o Brasil vem construindo no curso e no âmbito de sua República Federativa pode e deve ser dito misto, não porque nele meramente se justapõem, mas porque nele realmente se misturam dois sistemas alhures praticados isoladamente, o difuso (de origem norte-americana) e o concentrado (de origem austríaca), compenetrando um no outro, repercutindo a eficácia de um sobre a do outro, com mútuas e efetivas interações.

Nesse sistema, ocupa lugar ímpar o Senado Federal. Sua intervenção é uma forma sui generis, que aproxima o sistema difuso do concentrado, no que diz respeito à eficácia da norma inconstitucional. Dando seqüência a uma prática anterior, a Constituição da República Federativa do Brasil, promulgada em 5 de outubro de 1988, atribuiu a esse órgão variadas funções específicas, previstas em sua maioria no artigo 52, mas revestidas - todas elas - por duas funções gerais e basilares: a de representação dos estados-membros e a de moderação institucional. Somente nesse quadro funcional de representação e moderação é que se pode compreender devidamente a função especial de suspender a execução, no todo ou em parte, de lei declarada inconstitucional por decisão definitiva do Supremo Tribunal Federal, posta como privativa do Senado Federal pelo inciso X do artigo 52 da Constituição de $1988^{\prime \prime}{ }^{1}$

A Constituição da República promulgada em 5 de outubro de 1988 seguindo práticas anteriores deferiu a esse órgão competência 
privativa de suspender a execução, no todo ou em parte, de lei declarada inconstitucional, de maneira incidental, por decisão definitiva do Supremo Tribunal Federal, como vem previsto no inciso X do artigo 52.

A partir de 1934 o Supremo Tribunal Federal passou a ser o senhor da constitucionalidade e o Senado Federal o senhor da generalidade no que concerne ao controle difuso brasileiro.

A generalidade dos efeitos dessa decisão sempre coube ao Senado, cujo instrumento para promovê-la é a espécie normativa resolução. Essa divisão de competência no funcionamento do controle difuso está patente na Constituição brasileira, que convém destacar ela se refere ao controle difuso, chegando-se a essa efetivação, no ordenamento atual, através da combinação do caput do artigo 102 com o inciso $\mathrm{X}$ do artigo 52.

Ao Supremo incumbe a tarefa de decidir a constitucionalidade e ao Senado é atribuído à tarefa de generalizar os efeitos dessa decisão.

Nota-se que nesse caso a decisão definitiva do Supremo quando declara a inconstitucionalidade da lei, tem natureza declaratória e produz efeitos, somente, entre as partes envolvidas no litígio (inter partes) e, como regra, ex tunc, ou seja, retroativos à data da edição da lei ou ato normativo do Poder Público.

A partir daí poderá oficiar ao Senado Federal que através da espécie normativa resolução, querendo, por ser um ato discricionário, poderá suspender a execução no todo ou em parte do ato normativo que passará a produzir efeitos erga omnes assim que a norma for suspensa.

"tudo está a indicar que o Senado é o Juiz exclusivo do momento em que convém exercer a competência, a ele e só a ele atribuída, de suspender lei ou decreto declarado inconstitucional por decisão definitiva do Supremo Tribunal Federal. No exercício dessa competência cabe-lhe proceder com equilíbrio e isenção, sobretudo com prudência, como convém à 
tarefa delicada e relevante, assim para os indivíduos, como para a ordem".

Observa-se que no controle difuso há necessidade da participação de dois poderes da República para que a norma tida como inconstitucional deixe de produzir efeitos.

Em primeiro lugar compete ao Poder Judiciário solucionar a questão da constitucionalidade, pela via de exceção, que chega ao Órgão de Cúpula desse Poder através do recurso ordinário, do mandado de segurança, do hábeas corpus e do recurso extraordinário, porém só produz efeito entre as partes envolvidas na lide.

Posteriormente com a comunicação ao Senado Federal da decisão que através de um ato normativo resolução poderá suspender a execução da lei e só então a norma tida por inconstitucional passa a ter eficácia erga omnes, sendo um ponto pacífico.

\subsection{EFEITOS ORIUNDOS DA SUSPENSÃO DA LEI}

Todavia, quanto aos efeitos ex nunc ou ex tunc decorrentes da resolução do Senado que suspende a lei declarada inconstitucional, há sérias divergências doutrinárias.

Dentre os que defendem os efeitos ex nunc destacam-se, Sergio Resende que faz a seguinte assertiva:

“O Senado não atua como legislador negativo, revogando ou
desconstituindo a lei. Apenas a desativa: suspende-lhe a efi-
cácia. É o que consoa com a lógica do controle difuso, cuja
prática deve atendê-la sempre, mesmo se tratando de um
sistema misto. Sob pena de o difuso se tornar confuso. Por
isso mesmo, a resolução do Senado somente pode ter efeito
ex nunc. Não pode ter efeito ex tunc, nem pro futuro. Sua in-
tervenção constitui uma intersecção do sistema difuso com o
concentrado, que os aproxima entre si. Mas não os assimila,
nem os identifica, nem muito menos os confunde, um com o
outro. Pelo que, de um lado, essa intersecção não tem o efeito
ex tunc próprio do sistema difuso, porque não está julgando 
um caso concreto, e, de outro lado, porque não está julgando a lei em si, não tem possibilidade de modular no tempo - ex tunc, ex nunc ou pro futuro - a eficácia da decisão de inconstitucionalidade vinda do Supremo, ao qual o Senado não substitui. O Senado não é órgão de jurisdição constitucional”3

Ada Pellegrini afirma que neste caso a decisão judicial não se reveste da autoridade da coisa julgada, assim sobrevindo a suspensão da execução da lei, sua ineficácia, decorrente exclusivamente da resolução do Senado, terá efeitos ex nunc, se bem que devam ser ressalvadas as posições que sustentam que a ineficácia, mesmo nesse caso, seria ex tunc (GRINOVER, 2000. p. 11).

Lênio Luiz Streck, comungando com a opinião de Alexandre de Moraes, diz ser discutível que os efeitos da decisão suspensiva do Senado possam ter efeitos ex tunc e conclui que a razão está com aqueles que, como Alexandre de Moraes, sustentam os efeitos ex nunc da decisão suspensiva do Senado (STRECK, 2002. p. 376 s).

Por outro lado, há doutrinadores de renome que sustentam que os efeitos são ex tunc, destacando-se, Gilmar Ferreira Mendes: “ A suspensão constitui ato político que retira a lei do ordenamento jurídico, de forma definitiva e com efeitos retroativos (MENDES, Gilmar Ferreira. Direitos fundamentais e controle de constitucionalidade: estudos de direito constitucional. 2. ed. rev. ampl. São Paulo: Celso Bastos Editor, Instituto Brasileiro de Direito Constitucional, 1999. p. 390 s) e o saudoso Senador Accioly Filho:

"Já quando de suspensão se trata, o efeito é ex tunc, pois aquilo que é inconstitucional é natimorto, não teve vida (cf. Alfredo Buzaid e Francisco Campos), e, por isso, não produz efeitos, e aqueles que por ventura ocorreram ficam desconstituídos desde as suas raízes, como se não tivessem existido". ${ }^{4}$

Todavia, razão assiste àqueles que defendem que os efeitos são ex nunc, pois o Senado Federal apenas suspende a eficácia da lei declarada inconstitucional, desativando-a e jamais a revoga ou a des- 
constitui.

Na hipótese de o Órgão Senatorial permanecer omisso, por ser um ato discricionário, a lei ou o ato normativo emanado do Poder Público continua em plena vigência, podendo ser aplicados pelas demais Autoridades e pelos Tribunais, o que acarreta graves riscos e insegurança nas relações jurídicas, sem falar nas decisões contraditórias que poderão ocorrer.

Ademais disso, como se sabe, em regra, o Senado Federal quando toma conhecimento da decisão definitiva do supremo no caso in concreto não elabora a resolução para suspender a norma tida por inconstitucional e cada vez mais as partes aproveitam dessa inércia Senatorial para abarrotar a tão combalida máquina do judiciário de ações que já foram decididas, o que faz do Supremo Tribunal Federal um repetidor das mesmas decisões.

Tais práticas são indesejáveis e contribuem para a morosidade do Poder Judiciário, pois aumenta desnecessariamente o volume de trabalho da Suprema Corte que, nos últimos anos vem julgando entre 30.000 e 60.000 recursos extraordinários. $^{5}$

A Constituição Federal de 1988 conferiu ao Poder Judiciário a missão do controle judicial de constitucionalidade do tipo repressivo tanto no controle difuso como no concentrado, este realizado, somente, pelo Supremo Tribunal Federal.

Aqui, surge um problema que, atualmente, vem sendo alvo de mudança na interpretação do artigo 52 , X por alguns dos membros da Suprema Corte, o que se questiona é que no controle concentrado a decisão do Supremo Tribunal é bastante em si e os efeitos dela emanados são erga omnes, uma vez declarada a inconstitucionalidade da lei.

Contudo o mesmo não ocorre no controle difuso, pois neste, a mesma Corte com a mesma composição ao apreciar a constitucionalidade da mesma norma como última instância, o ordenamento 
jurídico só afasta sua aplicabilidade no caso concreto, permitindo que as instâncias inferiores continuem aplicando a norma tida por inconstitucional pela Corte Constitucional, obrigando esta a pronunciar novamente e ad infinitum.

\subsection{MUTAÇÃO CONSTITUCIONAL}

“(...) denomina-se mutação constitucional o processo informal de mudança da Constituição, por meio do qual são atribuídos novos sentidos, conteúdos até então não ressaltados à letra da Lex Legum, quer através da interpretação, em suas diversas modalidades e métodos, quer por intermédio da construção (construction), bem como dos usos e costumes constitucionais." ${ }^{6}$

Assim usando desse método os Ministros Gilmar Ferreira Mendes e Eros Roberto Grau na reclamação 4335-5/AC prolataram os votos com efeitos erga omnes na ação incidental de inconstitucionalidade, dando uma nova interpretação ao artigo $52, \mathrm{X}$ da Constituição Federal.

O Ministro Eros Grau sustentou em seu voto que "passamos em verdade de um texto [pelo qual] compete privativamente ao Senado Federal suspender a execução, no todo ou em parte, de lei declarada inconstitucional por decisão definitiva do Supremo Tribunal Federal, a outro texto: "compete privativamente ao Senado Federal dar publicidade à suspensão da execução, operada pelo Supremo Tribunal Federal, de lei declarada inconstitucional, no todo ou em parte, por decisão definitiva do Supremo".

A reclamação 4335-5/AC teve origem na decisão plenária do Colendo Supremo Tribunal Federal no HC no 82959, onde reconhecera por seis votos a cinco a inconstitucionalidade do parágrafo $1^{\circ}$ do artigo $2^{\circ}$ da Lei $\mathrm{n}^{\circ} \mathbf{8 . 0 7 2 / 9 0}$ que vedava a progressão do regime de cumprimento de pena nos crimes hediondos.

Entretanto, o Juiz da Vara de Execuções Penais de Rio Branco 
(AC) negou pedido de progressão de regime para dez condenados por crimes hediondos argumentando que por ter sido tomada essa decisão em sede de hábeas corpus pelo Supremo gerava efeitos apenas para aquele caso específico. "Para que venha a ter eficácia para todos, é necessária a comunicação da Corte Suprema ao Senado Federal, que, a seu critério, pode suspender a execução, no todo ou em parte, de lei declarada inconstitucional por decisão definitiva do Supremo Tribunal Federal (art. 52, X, da CF)", asseverou o Juiz.

E ponderou "se a decisão do Supremo Tribunal Federal tivesse sido tomada em sede de ação direta de inconstitucionalidade - Adin (controle concentrado), produziria eficácia contra todos e efeito vinculante, relativa aos demais Órgãos do Judiciário e até à Administração Pública direta e indireta". Como não ocorreu em pedido de Adin, dependeria do ato do Senado.

Inconformada a Defensoria Pública da União aforou contra a decisão a referida reclamação sustentando que o Juiz ao indeferir o pedido de progressão de regime para esses condenados por crimes hediondos, desobedeceu a decisão do STF que considerou inconstitucional a proibição da progressão.

0 Ministro Gilmar Mendes afirmou em seu voto "que qualquer decisão do Supremo Tribunal em controle difuso gera os mesmos efeitos que uma proferida em controle concentrado (abstrato)", assim agindo deu uma nova interpretação ao artigo da Constituição Federal com a finalidade de diminuir o acúmulo de trabalho e gastos públicos desnecessários, considerando que o Poder Constituinte Originário deferiu a Corte Suprema o encargo de guardiã da Constituição.

Os votos dos ministros conferindo efeitos erga omnes e vinculante às decisões do STF em sede de controle difuso de constitucionalidade respeitaram os princípios constitucionais do devido processo legal, da ampla defesa e do contraditório (art. 5.․, LIV e LV, da Constituição da República), quando decidiram o HC no 82959 e declararam a inconstitucionalidade do parágrafo $1^{\circ}$ do artigo $2^{\circ}$ da Lei $\mathrm{n}^{\circ} \mathrm{8} .072 / 90$. 
Assim sendo, se no controle concentrado as decisões do Supremo produz efeitos erga omnes por que razão não atribuir esse mesmo efeito a uma causa decidida em controle difuso, pois, certamente, as partes não atingidas por essa decisão ao aforar uma ação com a mesma finalidade a final ao chegar na Corte Suprema terá a mesma decisão, pois com certeza, os votos dos Ministros não vão ser modificados com tanta facilidade, pois ao prolatarem, assim o fizeram com convicção.

Pode, perfeitamente, uma decisão em sede de controle difuso ter a mesma eficácia que uma proferida em controle concentrado convivendo harmonicamente e ampliando o rol dos que possuem legitimidade ativa, pois na primeira qualquer pessoa que sentir prejudicado poderá ingressar com a ação em Juízo, ou mesmo ser reconhecida ex officio, enquanto que na segunda o rol dos legitimados está taxativamente previsto na Constituição Brasileira, cujo resultado final terá efeitos erga omnes ocorre, aqui, a ponte entre o controle difuso-concreto e o controle abstrato-concentrado.

Com esses votos na reclamação 4335-5/AC os Ministros estão " reivindicando o "monopólio da última palavra" no que concerne a temas de interpretação constitucional, abeberando-se em precedentes jurisprudenciais da própria Corte como guardiã da Constituição Federal que é o Supremo Tribunal Federal.

"Não existe a Constituição de 1.988. o que hoje realmente há, aqui e agora, é a Constituição do Brasil, tal como hoje, aqui e agora, ela é interpretada/aplicada por esta Corte"?

Há doutrinadores de escol sustentando que o Supremo Tribunal Federal poderá conferir efeito erga omnes no controle difuso de constitucionalidade, quando a decisão for proferida pelo plenário, dentre eles, Cezar Roberto Bitencourt assim afirmou ao comentar a decisão proferida no Hábeas Corpus nº 82.959/06:

"Essa decisão, na realidade, tornou sem objeto a competência do Senado Federal, como destaca Luiz Roberto Barroso: a 
verdade é que, com a criação da ação genérica de inconstitucionalidade, pela $\mathrm{EC}$ nำ16/65, e com o contorno dado à ação direta pela Constituição de 1988, essa competência atribuída ao Senado tornou-se um anacronismo".

\section{CONCLUSÃO}

Nota-se que, atualmente, no controle difuso de constitucionalidade a decisão definitiva emanada do Supremo Tribunal, somente, produz efeitos entre as partes litigantes, ficando essa decisão dependendo da elaboração de uma resolução senatorial para que ela produza efeitos contra todos (erga omnes), que como visto, o mesmo não está obrigado a suspender a lei declarada inconstitucional, mesmo depois de oficialmente comunicado da decisão pelo Supremo Tribunal Federal por se tratar de um ato discricionário que só suspenderá a lei, após um Juízo de conveniência e oportunidade.

Assim a decisão emanada da Corte Suprema para estender seus efeitos a todos os cidadãos fica dependendo da manifestação de outro Poder da União (Senado Federal), o que não passa de um engessamento com que o Brasil atou o sistema difuso, pois a decisão definitiva do Supremo Tribunal Federal, no caso concreto, só produz efeitos entre as partes litigantes.

A questão há que ser resolvida, urgentemente, a bem da harmonia e correção do sistema misto adotado pelo Brasil.

Assim, salvo melhor Juízo, uma das propostas que resolverá, adequadamente, a questão está exposta neste excelente trabalho:

"Quando a Corte Constitucional cumula as competências de controle concentrado e de última instância do controle difuso, tal como ocorre no Brasil, surge um problema de coerência. Se o ordenamento jurídico aceita que uma Corte possa eliminar de maneira inapelável e geralmente vinculante uma norma inconstitucional, como admitir que a mesma Corte com a mesma composição, quando aprecia a constitucionali- 
dade da mesma norma como última instância do controle difuso só possa afastar sua aplicação no caso concreto? E como admitir que se as instâncias inferiores aplicam a norma tida por inconstitucional pela Corte constitucional, essa última deva se pronunciar e ad infinitum?

Temos aqui uma situação que, além de carecer de justificativa política e de agredir princípios de racionalidade processual, gera conseqüências práticas indesejáveis, agravando a morosidade do Poder Judiciário e aumentando desnecessariamente o volume de trabalho da Suprema Corte.

E continua Por mais que isso seja contraprodutivo, não há como negar que a Constituição Federal:

- mantém a paralelidade dos mecanismos processuais do controle difuso e concentrado;

- não autoriza o afastamento definitivo de dispositivo infraconstitucionais no âmbito do controle difuso realizado por órgãos do Poder Judiciário.

Diante disso são possíveis duas posturas do Supremo Tribunal Federal:

Primeiro, admitir que exerce, de constitutione lata, um duplo papel no âmbito do controle de constitucionalidade, sendo suas tarefas diferentes em cada caso. Adotando essa perspectiva, o Tribunal poderia deixar claro seu desconforto com o sistema atual de controle de constitucionalidade e formular um apelo ao legislador para adotar medida de simplificação do sistema de controle.

Segundo, o Tribunal poderia tomar a iniciativa (e assumir a responsabilidade) de decidir de maneira contrária a dispositivos constitucionais, criando novas regras de competência que, a juízo do próprio Tribunal, permitem evitar a duplicidade de papéis e o problema da morosidade acima". 
Portanto fica claro que da forma como yem estruturado, o controle difuso de constitucionalidade merece reparos com urgência e uma solução para por fim a essa questão é a mutação constitucional como se extrai na reclamação 4335-5/AC com votos dos Ministros Gilmar Mendes e Eros Grau, pois eles entendem que vale para todos, independentemente de o Senado se manifestar ou não.

O Senado não pode "restringir ou ampliar a extensão do julgado proferido pelo Supremo Tribunal Federal", ponderou o Min. Gilmar Mendes. "A decisão do Senado é ato secundário ao do Supremo", sustentou o Min. Eros Grau.

"Se o Supremo Tribunal pode, em ação direta de inconstitucionalidade, suspender, liminarmente, a eficácia de uma lei, até mesmo de uma Emenda Constitucional, por que haveria a declaração de inconstitucionalidade, proferida no controle incidental, valer tão-somente para as partes?

A única resposta plausível indica que o instituto da suspensão pelo Senado de execução da lei declarada inconstitucional pelo Supremo assenta-se hoje em razão de índole exclusivamente histórica."(MENDES, 1998, pp. 376/377).

\section{REFERÊNCIAS BIBLIOGRÁFICAS}

ALMEIDA NETO, Manoel Carlos de. Antecedentes históricos do controle difuso de constitucionalidade das leis (the lead case Marbury v. Madison). Jus Navigandi, Teresina, ano 8, n. 474, 24 out. 2004. Disponível em: <http://jus2.uol.com.br/doutrina/texto. asp?id=5838>. Acesso em: 06 nov. 2007.

ADIN 3.367, rel. Min.. Cezar Peluzo, j. 13-4-2005.

BASTOS, Celso Ribeiro, Curso de Direito Constitucional, $5^{\mathbf{a}}$ ed., São Paulo Saraiva, 1982.

BONAVIDES, Paulo. Curso de Direito Constitucional. 13aㅗ ed. São 
Paulo: Malheiros, 2003.

BROSSARD, Paulo. O Senado e as leis inconstitucionais. Revista de Informação Legislativa no 50/55.

BITENCOURT, Cezar Roberto. Tratado de Direito Penal - Parte Geral, v. $1,4^{\circ}$. ed., Saraiva.

BULOS, UADI LAMMÊGO. Mutação Constitucional. São Paulo: Saraiva, 1997.

DANTAS, Ivo. Constituição \& Processo - $2^{\underline{a}}$ ed., revista, atualizada e ampliada, editora Juruá.

DE FIGUEIREDO Dantas, Paulo Roberto. Direito Constitucional Editora Atlas- S/A - 2005.

DIMOULIS, Dimitri e LUNARDI, Soraya Regina Gasparetto Construção do processo constitucional-objetivo (artigo, ainda não publicado, cedido pelo autor em sala de aula.

" Estatística do movimento processual entre 2000 e 2007 publicadas em www.stf.gov.br. Acesso em 15 de dezembro de 2007.

FERREIRA Mendes, Gilmar. Direitos Fundamentais e Controle de Constitucionalidade - Estudos de Direito Constitucional, Celso Bastos Editor, 1998.

GRINOVER, Ada Pellegrini. A marcha do processo, Rio de Janeiro: Forense Universitária, 2000.

MORAES, Alexandre de. Direito Constitucional. 7a edição. São Paulo: Atlas, 2000.

RESENDE DE BARROS, Sérgio. O Senado e o controle de constitucionalidade. Disponível em http:// www.academus.pro. $\mathrm{br} /$ professor/ivanclementino/0\%20senado $\% 20$ controle $\% 20$ 
de\%constitucionalidade.doc. Acesso em 10 de dezembro de 2007. RTJ $162 / 765$.

STRECK, Lenio Luiz; OLIVEIRA, Marcelo Andrade Cattoni de et al. A nova perspectiva do Supremo Tribunal Federal sobre o controle difuso: mutação constitucional e limites da legitimidade da jurisdição constitucional. Jus Navigandi, Teresina, ano 11, n. 1498, 8 ago. 2007. Disponível em: <http://jus2.uol.com.br/doutrina/texto. asp?id=10253>. Acesso em: 31 out. 2007.

STRECK, Lenio Luiz. Jurisdição constitucional e hermenêutica: uma nova crítica do Direito. Porto Alegre: Livraria do Advogado, 2002. www.estadao.com.br.

\section{NOTAS}

${ }^{1}$ RESENDE DE BARROS, Sérgio. O Senado e o controle de constitucionalidade. Disponível em http://www.academus.pro.br/ professor/ivanclementino/ $0 \% 20$ senado $\% 20$ controle $\% 20$ de\%constitucionalidade.doc. Acesso em 10 de dezembro de 2007.

${ }^{2}$ BROSSARD, Paulo. 0 Senado e as leis inconstitucionais. Revista de Informação Legislativa nº 50/55.

${ }^{3}$ RESENDE DE BARROS, Sérgio. O Senado e o controle de constitucionalidade. Disponível em http://www.academus.pro.br/ professor/ivanclementino/ $0 \% 20$ senado $\% 20$ controle $\% 20$ de\%constitucionalidade.doc. Acesso em 10 de dezembro de 2007.

${ }^{4}$ BRASIL. Congresso, Senado Federal, Parecer no 154 , de 1971, Rel. Senador Accioly Filho, Revista de Informação Legislativa, 12(48):266/8.

${ }^{5}$ Estatística do movimento processual entre 2000 e 2007 publicadas em www.stf.gov.br. Acesso em 15 de dezembro de 2007. 
${ }^{6}$ BULOS, UADI LAMMÊGO Mutação Constitucional; São Paulo: Saraiva, 1997, pág. 54

${ }^{7}$ ADIN 3.367, rel. Min.. Cezar Peluzo, j. 13-4-2005.

${ }^{8}$ BITENCOURT, Cezar Roberto. Tratado de Direito Penal - Parte Geral, v. 1, 4‥ ed., Saraiva, p. 456.

9 DIMOULIS, Dimitri e LUNARDI, Soraya Regina Gasparetto Construção do processo constitucional-objetivo (artigo, ainda não publicado, cedido pelo autor em sala de aula. 